\title{
LOS MORISCOS EN ARGELIA: ASENTAMIENTO SOCIAL Y DESARROLLO PROTOINDUSTRIAL
}

\author{
Nacira Bendimerad-Benosman \\ Universidad de Tremecén
}

\begin{abstract}
Resumen
E1 Mediterráneo vio atravesar como una ola a cientos de personas en busca de refugio y exilio a principios del siglo xvir. Los moriscos españoles fue una comunidad reducida a un vestigio del pasado en términos políticos, y condenada a la extinción en términos sociales. El tema que vamos a desarrollar en el presente artículo es la llegada de estos refugiados al Magreb central y su instalación, influencia y contribución a la vida cotidiana de la sociedad en la que fueron acogidos.
\end{abstract}

Palabras clave: Moriscos, Magreb central, exilio, vida cultural, premodernidad, protoindustrialización.

\begin{abstract}
At the beginning of the century, hundreds of people, who were seeking refuge and exile, crossed like a wave the Mediterranean sea. The Moriscos were a community that was politically reduced to a remnant of the past, and socially condemned to extinction. In this article, we will present and develop the arrival of these refugees to the Central Maghreb. We will talk about their settling, their influence and their contribution to the daily life of the society that welcomed them.
\end{abstract}

Keywords: Moriscos, Central Maghreb, exile, cultural life, premodernity, protoindustrialization.

\section{LLEGADA E INSTALACIÓN}

Las ciudades del litoral central magrebí fueron los lugares que recibieron los flujos de los deportados musulmanes convertidos al cristianismo, los 1lamados moriscos ${ }^{1}$. Expulsados de su tierra natal, llegaron por los diferentes puertos de las ciudades costeras del Magreb central: Orán, Mazalquivir, Argel y Bugía. Los puertos de Orán y Mazalquivir fueron

$1 \mathrm{El}$ presente artículo es fruto de la investigación que realizamos para nuestra tesis doctoral titulada La primera deportación masiva humana de la época moderna: estudio del caso de los moriscos y de sus migraciones hacia el Magreb Central (1609-1614), defendida en 2013, en la Universidad de Tremecén, Argelia. 
los testigos de los primeros desembarques del año de i6o9. Como ya se sabe, aquellos puertos ocupados por la Corona española recibieron los barcos y navíos de ésta. Las demás ciudades, tales Tenés, Cherchell, Argel y Bugía, serán los puntos que recibirán los barcos turcos y los navíos particulares que pagaron los moriscos con sus propios medios.

Tremecén recibió su contingente de exiliados desde la ciudad de Orán, la cual, estando bajo el gobierno de la Corona española, no quería albergarlos bajo ningún concepto. Mazalquivir y Arzew fueron también puertos que recibieron junto a Mostaganem a expulsados. En cuanto a Argel, bajo el mando turco, acogió en su seno a aquella comunidad a lo largo del siglo xvi y, en la época de la gran expulsión, aprovisionó al mismo tiempo a la ciudad de Bugía, la cual tenía ya una comunidad andalusí que había llegado en el siglo xvi, en tiempo de la ocupación hispánica de la ciudad, y después de su salida forzada, provocada por los turcos ${ }^{2}$.

En aquella época, período moderno del Xviı, ninguna deportación parecida se había decidido y efectuado por nación alguna. La decisión drástica e inhumana fue única en el mundo de principios del siglo XVII. Las naciones francesa e inglesa, ora aliadas ora enemigas de la Monarquía española, a través de sus hombres de letras y de sus políticos, mostraron su asombro, luego su compasión hacia las víctimas, condenando las acciones de Felipe III, o dándole razón de querer salvar la unidad religiosa de su territorio.

\section{El ORANESADO}

Los españoles siguieron una política drástica, según preceptos del Cardenal de Cisneros: "Quería plantar la cruz en aquella tierra musulmana y, después de haber echado en África a los antiguos conquistadores de España, perseguirles y exterminarlos" ${ }^{3}$. Quería también poner fin a las depredaciones de los corsarios turcos, y destrozar en el Mediterráneo occidental la potencia temida del sultán de Constantinopla.

2 Véase el clásico de Diego de Haedo. Manejamos la traducción de Berbrugger y Monnereau, Topographie et histoire générale d'Alger, Argel, Grand Alger du livre, 2004.

3 Paul Rufe, Domination espagnole à Oran. Le gouvernement du Comte d'Alcaudete 1534-1558, Argel, Mimouni, 2000, pp. 1-2. 
Las dos influencias, la española y la otomana, iban a enfrentarse en la región de Tremecén por su situación, en tanto que capital de un reino: "Tremecén era una ciudad grande y real", "era el centro politico de toda la región" " , la ciudad principal del comercio de aquella parte de África. Desde tiempo atrás, era el depósito de las mercancías llevadas desde las orillas del mar, y transportadas en las caravanas hacia el Sudán y Guinea. A partir de la ocupación de Orán por los españoles, One y Rachgún (Haresgol) sirvieron de puertos para Tremecén ${ }^{6}$, reemplazando así el puerto principal de la región oeste, Orán.

La única meta era impedir que los turcos dominaran la región oeste del Magreb central, como lo hacían en el centro y en el este. Para eso, los españoles del presidio querían cerrar las puertas de Tremecén y, al mismo tiempo, deshacerse de los otomanos que estaban en Mostaganem, la que servía de "cuartel general y punto de partida de los ataques turcos dirigidos en contra de Orán en el siglo XV" ${ }^{7}$. Eran los dos puntos esenciales a los que tenía que llegar el gobierno de Orán.

\section{Tremecén, sede de la dinastía zianí}

Tremecén era la capital de un reino que abarcaba toda la superficie que ocupaban las ciudades de Orán, Tenes, Cherchell, Argel y Bugía: "Tremesin está en el continente africano a 30 millas de Orán y es más grande que Valencia", afirmará el viajero alemán Münzer ${ }^{8}$.

Tremecén está situada sobre una altura, por encima de una cadena de rocas que el geógrafo al-Idrisi llamó Sakhratayn, y en la cima de esta cadena se encuentra una meseta bastante grande de donde brota una multitud de manantiales que, reuniéndose, forman riachuelos y cascadas rumbo hacia la urbe. Shaw, viajero inglés, fue testigo de este hecho'. Por

4 Léon l'Africain, Description de l'Afrique, trad. Perrot Ablancourt, Paris,1667, p. 593.

5 Rufe, ob. cit., p. 167.

6 Ibid., p. 12

7 René Lespès, “Oran, ville et port avant l'occupation française (1831)”, Revue africaine, 1934, núm. 75 p. 223.

8 Jérôme Münzer, Voyage en Espagne et au Portugal 1494-1495, trad. Michel Tarayre, París, Les Belles Lettres, 2006, p. 80.

9 Thomas Shaw, Voyage dans la régence d'Alger au XVIII siècle, trad. Mac Carthy (1830), Argel, Grand Alger du livre, 2007, p. 131. 
su situación y esos testimonios, Tremecén siempre se llamó Ciudad de los manantiales.

En cuanto a Le Cocq, en tiempo de la ocupación francesa de Tremecén en 1836, afirmaba que la ciudad había producido una profunda impresión sobre las tropas. El lugar, la hierba, el agua abundante sedujeron a los soldados:

En ninguna parte de Argelia la vegetación presenta tanta alegría ni tanto frescor. Las aguas son abundantes y bellas, el suelo es fértil de manera admirable. La montaña presenta resaltos que forman tantos pisos cubiertos con tierra vegetal, donde crecen plantas de Europa y de África, entremezcladas, separadas, mezcladas de nuevo según la elevación y la disposición de los lugares ${ }^{10}$.

Lebas, por su parte, tratando de la vida económica de la ciudad, afirmará que "la industria consiste en fábricas de pólvora de guerra, en arreos, cuenta también con algunos armeros y zapateros" ${ }^{11}$. Aquellas profesiones, aunque existían en tiempo de los zianíes, se vieron reforzadas con la llegada de los moriscos en la ciudad, y la artesanía llegó a su apogeo, después de su instalación en los diferentes espacios de la misma. El impacto traspasó las fronteras no sólo terrestres sino también marinas. Los productos se vendieron o se intercambiaron en Oriente, en el norte y en el sur del Magreb central. La población de Tremecén se componía de mercaderes, de artesanos, de estudiantes y de nobles; estos ocupaban los principales cargos y dirigían la armada y las provincias.

Después de la toma de los presidios por los españoles, el gobernador de Orán intentó conquistar la capital, cada vez que la ocasión se presentaba. Para eso, tenía una red de espías judíos que le enviaban diariamente cartas, dándole cuentas de la actividad política y económica de la sede del reino. A pesar de eso, viendo que la cosa era imposible y, después de muchas pérdidas de vidas, el gobierno de Orán impuso el pago de tributos a cambio de no entrometerse en la vida de la ciudad.

Los andalusíes recién llegados se instalaron en los alrededores de la capital, en Ain Fezza, Uled sidi Ali Belhadj, El Eubad. En cuanto a los

10 Nuestra traducción. “L'occupation de Tlemcen en 1836”, en Revue africaine, p. 645.

11 P.H. Lebas, Dictionnaire de la France, univers pittoresque, 1845, tomo XII, p. 686. 
que encontraron a parientes o amigos, se instalaron cerca de ellos en el corazón de la ciudad. Esos parientes habían llegado mucho antes que ellos, ya que los musulmanes de al-Andalus empezaron a llegar a partir de la época de la toma de Toledo y Sevilla, luego después de la toma de Granada, hasta llegar la época de la expulsión final. A continuación, tenemos un testimonio de un escritor tremecení que se interesó por aquella comunidad:

Tremecén siempre ha atraído a personas de todas partes, pero son los andalusíes que vinieron con gran brillo aportando con ellos todo el uso social de una civilización, la cual llegó a altas cimas en todos los terrenos, relaciones humanas, ambiente familiar refinado, con sus vestidos específicos, su comportamiento respetuoso del medio ambiente donde viven, y aportando su entera contribución en los terrenos religiosos, letras y ciencias, música, artesanía, agricultura ${ }^{12}$.

\section{Orán, la Corte chica española}

Construida hacia el año de 903 por marineros andalusíes en tiempo de los Omeyas de al-Andalus, Orán se verá a partir de ahí conquistada y reconquistada, destruida y renacida por dinastías que se sucederán y desfilarán a lo largo de las épocas. León el Africano la describe así:

La ciudad contiene 6.000 fuegos, los catalanes y los genoveses vienen para hacer comercio, la mayoría de los habitantes son artesanos y tejedores de tela; la ciudad, llena de edificios y de todas las cosas que convienen a una buena villa, tal como colegios, hospitales, baños públicos y hostelería, está rodeada por bellas murallas ${ }^{13}$.

Orán que brillaba por su lujo y el destello de sus fiestas era llamada en España la Corte chica. El Bekri, en su descripción de la ciudad, decía que Orán era una plaza fuerte y que poseía aguas corrientes, molinos de agua y jardines; añadiendo que su rada ofrecía una buena invernada contra los vientos ${ }^{14}$. Ibn Hawqal, siguiendo el mismo orden de ideas, afirmaba

12 Nuestra traducción. Ghouti Charif, L'arbre de Tlemcen, Tremecén, Imprimerie régionale Sari, 1993, p. 10.

13 Léon l'Africain, ob. cit., p.120.

14 Abou Obeid El Bekri, Description de l'Afrique septentrionale, trad. de Slane, París, Imprimerie 
que "el puerto estaba tan seguro y tan bien abrigado contra los vientos que no pienso que haya semejante a él en todos los países de los Beréberes" 15.

La población de Orán contaba aproximadamente con 7.000 habitantes según el comandante Vallejo; había hasta familias de sangre noble. Otro testimonio del geógrafo Münzer nos enseña que había relaciones comerciales entre Orán y el sur de la península ${ }^{16}$. Vallejo confirma este hecho con estas palabras: "Hemos visto en el puerto de Almería un barco cargado con higos, habas, arroz y otros alimentos que iba a Orán" ${ }^{17}$.

Había también comercio con Málaga, la cual junto con Cartagena aseguraba el abastecimiento de Orán y Mers el Kébir, según Braude18 ${ }^{18}$. ¿Por qué Málaga? La razón es que había sido escogida como sede de la logística del abastecimiento norteafricano, por su situación geográfica considerada como estratégica. Así, tuvo un papel prioritario en la organización de las empresas de conquista de Mers el Kébir, del Peñón de Vélez, de Orán y de Bugía ${ }^{19}$.

Por otro lado, Paul Rufe, igual que León el Africano, al describir la ciudad de Orán, evocaron ambos el comercio que se hacía con Cataluña y Génova. Estas regiones europeas habían tenido, en todo tiempo, relaciones comerciales con el reino de los Beni Abdelwad. El trato había empezado en la Edad Media y duró a lo largo de la Edad Moderna, hasta principios del siglo XIX.

Los españoles, después de ocupar Orán y Mazalquivir, se encontraron frente a la hostilidad de las tribus nómadas de la región. Dándose cuenta de la situación, se encerraron en el interior de la plaza y su vida cotidiana se resintió. La estación reguladora de Málaga, como queda dicho más arriba, ayudada por los servicios de Cartagena, aseguraba el abastecimiento del sector oeste del Magreb: Orán, Mazalquivir y Melilla ${ }^{20}$. Sin

impériale, 1859, pp. 165-188.

15 Description des routes et de l'Afrique, trad. de Slane, Journal asiatique, 1842, pp.186-187

16 Ob. cit., p. 80

17 Revue africaine, 1925, núm. 66, p. 349.

18 Fernand Braudel, La méditerranée et le monde méditerranéen à l'époque de Philippe II, París, Armand Colin, 1949, vol. II, p. 280.

19 René Quatrefages, «La proveeduría de las armadas. De l'expédition de Tunis à celle d'Alger», Mélanges de la casa de Velázquez, 1978, vol. 14, pp. 214-247.

20 Según Fernand Braudel cada plaza era el feudo de su Capitán general. Orán por largo tiempo fue el de la familia de los Alcaudete, como Trípoli fue el patrimonio de Hugo de Moncada, y Melilla 
embargo, el dinero y la comida tardaban en llegar desde la Península. La vida en el presidio era seguramente miserable y los soldados pasaban hambre todo el año; vivían como las tripulaciones de los barcos, sin saber lo que comerían al día siguiente. Por eso se vieron forzados a salir de su islote para hacer razias, con la ayuda de los llamados "moros de paz" que les servían de guías y de acompañantes. Las razias eran salidas calculadas que tenían una estricta necesidad, y eran como un deporte; para Braudel: "Habia que patrullar en torno a la fortaleza, dispersar a los unos y proteger a los otros, tomar rehenes, obtener informes y apoderarse de viveres" 21.

Estas incursiones impedían el indispensable contacto pacífico entre las regiones interiores y la fortaleza, difundiendo así el terror a lo español. Por eso, José Vallejo mostró su descontento en cuanto a este recurso para procurarse alimentos, dinero y prisioneros. Dijo que eran jornadas que se parecían mucho "a las incursiones de los tártaros en Hungria, en Polonia y en otras regiones vecinas. Los españoles se conducian en todo como bárbaros" 22 . Para él, el gobierno de Orán hubiera tenido que obrar lo más posible para desarrollar las relaciones de los mercaderes con las tribus fuera de la plaza. La vida hubiera sido más soportable con el apoyo comercial, y de allí la política hubiera cambiado el estado de las cosas: "Nosotros los españoles, nos señalan siempre por nuestra negligencia cuando se trata de desarrollar nuestro comercio" ${ }^{23}$.

El hecho de no aceptar ni a los judíos expulsados en primer lugar, ni a los moriscos desterrados en segundo lugar, fue un punto negativo para la vida en el presidio ${ }^{24}$. Fue la causa del decaimiento de la ciudad y del hecho de que fuera considerada únicamente como una guarnición militar ${ }^{25}$.

En este sentido, los presidios que se negaron a acoger a los expulsados fueron lugares de deportación, adonde se enviaba a purgar sus penas y sus condenas, a gente noble y rica ${ }^{26}$. Beatriz Alonso estima que la dominación

el de los Medina Sidonia. Cf. ob.cit., p. 281.

21 Ibidem.

22 José Vallejo, “Mémoire sur l'état et la valeur des places d’Oran et de Mers el Kébir”, trad. Jean Cazenave, Revue africaine, 1925, pp. 45-47.

23 Idem., p.29

24 Hay que subrayar el hecho de que, a pesar de todas las prohibiciones, hubo en la composición de la población de Orán judíos y moriscos; los primeros se quedaron hasta el año de 1668.

25 René Lespes, Revue africaine, 1934, núm. 75, p. 304.

26 Braudel, ob. cit., p. 280. Fue el caso del nieto de Colón, Luis, quien murió en Orán, condenado 
española en Berbería fue irreal, las ventajas económicas obtenidas, mínimas, y la expansión cristiana, el verdadero objetivo de aquella dominación, casi inexistente. En efecto, el verdadero enemigo que había que combatir no era el musulmán de los alrededores, sino el hambre: "Los resultados nefastos de aquella ocupación restringida no tardaron en hacerse sentir: en la mañana misma de su victoria los vencedores se convertian en vencidos, los conquistadores volviéndose los sitiados" 27.

\section{Mostaganem}

Dos plazas principales situadas ambas en el litoral, Tenes y Mostaganem, habían provocado desde el principio la codicia de las dos potencias interesadas, la española y la otomana. Cada una quería tenerlas bajo su mando por razón de su situación estratégica.

Situada al este de Orán, muy próxima de ésta, Mostaganem era otro puerto que la Corona española ansiaba obtener. Después de la conquista del cardenal de Cisneros, Mostaganem había pagado tributo. Una gran prosperidad caracterizaba aquella ciudad gracias a la fertilidad de su territorio. La ciudad estaba fortificada y rodeada por murallas. Los otomanos no tardaron en hacer de ella uno de sus puestos militares más importantes. De ahí se explican las numerosas expediciones de las cuales fue el blanco. Expediciones cristianas mandadas todas por el gobernador y conde de Alcaudete, expediciones que acabaron con muchas víctimas por ambas partes, y con la muerte del mismo conde ${ }^{28}$. Por su parte, Shaw nos hace su descripción de Mostaganem, diciendo:

Se eleva como un anfiteatro a orillas del mar; pero está rodeada de montañas, por todas partes, del lado del campo. Aquella ciudad, un poco más grande que Orán, es después de Tremecén, la más considerable de la provincia. La fuerza de Mostagán consiste en una ciudadela construida en sus alturas, manda la ciudad y el país alrededor ${ }^{29}$.

por trigamia a 10 años de destierro.

27 Jean Cazenave, “Contribution à l'histoire du vieil Oran”, Revue africaine, 1922, núm. 63, p. 227.

28 Rufe, ob.cit., p. 18.

29 Shaw, ob.cit., p.128 
En tiempo de la expulsión, numerosos exiliados fueron evacuados hacia aquella ciudad. Muchos no llegaron a destino porque fueron atacados y saqueados durante el camino y muchos fallecieron. Sin embargo, los que pudieron llegar sanos y salvos se instalaron y crearon un paraíso en las tierras fértiles que encontraron. Los cultivos nuevos que trajeron los moriscos con ellos hicieron de la región una parte productora y comercial en el terreno agrícola. Del lado cultural, su música hizo hablar de ella, y el bauzi de Mostaganem lo aprecian los argelinos y los árabes en general.

\section{LA REgión DE Argel}

Cherchell y Argel, ciudades muy próximas, eran un blanco para cualquier dominio estratégico del norte de África. La Corona española tenía bajo fianza a Cherchell, la cual paga un tributo. Los otomanos no tardaron en apoderarse de la ciudad, utilizándola como fuente de aprovisionamiento que, gracias a su abundancia en agua, tenía una gran riqueza en productos agrícolas.

En cuanto a Argel, como capital de la Regencia y eje de la presencia otomana en el Magreb central, era el deseo inmediato e irresistible del gobierno español. Para tener Argel bajo su mando muchas intentonas se llevaron a cabo; todas desembocaron en derrotas, ora amargas ora estimulantes. De todos modos, la capital nunca se pudo tomar, por eso, España se volvió hacia otros horizontes y conquistó otras ciudades del litoral centro magrebí. Las costas eran lo que le interesaba, para poder controlar el tráfico mediterráneo.

\section{Argel}

Configurada como la tercera de las provincias del reino de Tremecén, la situación de Argel entre las provincias de Tenes y Bugía y su proximidad al reino de Túnez siempre le confirió unas características específicas de gobierno. La dinastía zianí sólo estuvo al frente de los destinos de Argel durante un tiempo, antes de que esta provincia se vinculara con las autoridades de Bugía. La progresiva entrada de los españoles en las 
costas norteafricanas y, en especial, su conquista de Bugía en I5Io, hicieron declinar la dependencia de Argel respecto de la provincia vecina ${ }^{30}$.

Los otomanos llegan a Argel y la ocupan después de la petición de ayuda que reciben para liberar la población de la presión que ejercen los soldados imperiales desde la fortaleza del Peñón. El odio a los cristianos y el bien del Islam, a los que hay que añadir la defensa de los intereses de la Sublime Puerta, son los objetivos que mueven a los hermanos Barbarroja a recorrer todo el Mediterráneo, y padecer mil penalidades. $\mathrm{Su}$ lema era: "es mejor morir que entregar las armas. ¿Qué miedo puede darle a uno la muerte? El hombre muere una vez, pero su fama no muere nunca" ${ }^{31}$.

Su fidelidad al sultán del mundo como máxima autoridad religiosa y política de la tierra, hace de Kheireddine y Arroudj, unos 'auténticos musulmanes' que no combaten por motivos terrenales sino por el ensalzamiento de la fe.

Kheireddine Barbarroja es una figura casi legendaria. Alcanza la gloria y el éxito militar y social por medio de su inteligencia y su esfuerzo; es la historia de la victoria absoluta de las armas de Solimán el magnífico, en el Mediterráneo. ${ }^{32}$ Su llegada a Argel fue sinónimo, según la misma fuente, de la reimplantación del orden y del buen gobierno. Sin embargo, sus acciones fueron crueles y duras sobre todo en el caso del asesinato del gobernador de la ciudad de Argel, destituyendo así el poder local y asentando el suyo.

La etapa siguiente de Kheireddine, tan pronto instalado en la cabeza de la Regencia de Argel, fue acabar con los españoles del Peñón que "eran una molestia y una vergüenza, y un obstáculo para los movimientos de la marina. Impedian la construcción de un puerto y los barcos no estaban en seguridad ni contra las tempestades ni contra los ataques enemigos" 33.

El Emperador Carlos v siente un gran peso al pensar en aquella figura simbólica y es una de sus preocupaciones esenciales, después de la toma del Peñón. Con rabia y frente a la situación reclama:

30 Beatriz Alonso Acero, Cisneros y la conquista española del norte de África: cruzada, política y arte de la guerra, Madrid, Ministerio de Defensa, 2005, pp. 124-125.

31 Y. Oztuna, Bárbaros Hayreddin Pasa'nin Hatiralari, Estambul, 1989, p. 45.

32 Idem, p.139

33 Belhamissi, Moulay, Marine et marins d'Alger, Oran, Dar el Gherb, t. II, 1996, pp.28-29 
¿Cómo puede tomar un castillo mío un ladrón del mar como Barbarroja? Yo, que hice prisionero y eché en los calabozos de Madrid a un rey como el de Francia, no he podido vencer a este corsario. La culpa es de mis generales y almirantes que carecen de celo. Me habéis deshonrado ${ }^{34}$.

En 1529, el puerto fue reconquistado, lo que permitió a los argelinos lanzarse mejor en la guerra del corso. España pierde pues una guarnición y un punto estratégico. Lo que ayudó al corso y a su organización fue la construcción de los barcos, que se efectuaba en la misma Argel. En Haedo leemos "los navios fabricados con la madera del pais eran ordinariamente muy ligeros” ${ }^{35}$, y entonces más rápidos y más eficaces para los provechos corsarios. La madera provenía de los montes de Cherchell, excelente manantial tomado del pino y del roble. Como aquella ciudad estaba poblada por moriscos de Granada, de Valencia y de Aragón, ellos pasaron por maestros en la construcción de los barcos ${ }^{36}$.

El gobierno de la Regencia reaccionaba a veces violentamente cuando los intereses musulmanes en Occidente o en Oriente estaban amenazados. Ayudar a los correligionarios estaba considerado como el más sagrado de los deberes. En tanto que buen musulmán, el rescate de los moriscos tiene el mismo carácter de realización de una de las obligaciones del mismo, además de la culminación de un encargo divino, el de salvaguardar al Islam del azote de los infieles, que cuenta con el beneplácito de Solimán el magnífico ${ }^{37}$.

La Regencia no podía ignorar el drama de aquellos musulmanes librados a los verdugos fanáticos de Jiménez y al sistema inquisitorial. Gracias a la marina, una asistencia militar y material fue asegurada para los infortunados, o para defenderse, o para venir a tierra del Islam:

E1 Magreb central había recibido centenares y miles de andalusíes, llenos de ambición e hirviendo del deseo de encontrar una compensación para los bienes perdidos, de allí la hostilidad implacable contra España ${ }^{38}$.

34 Palabras de Carlos v después de la toma del peñón de Argel. Véase Oztuna, ob.cit., pp. 69-70. 35 Haedo, Topographie d'Alger, Revue africaine, 1870, núm. 14, pp. 414-433.

36 Haedo, ob. cit., 2004, p. 51.

37 Miguel Ángel de Bunes Ibarra, La ocupación del Magreb por Hayreddin Barbarroja según Ms. 2459 de la üniversite Kütüphanesi de Estambul, en M. ${ }^{a}$ J. Rubiera Mata (coord.), Carlos V, los moriscos y el islam, Alicante, Universidad de Alicante, 2000, p. 186.

38 Bunes Ibarra, ob.cit., p. 152. Braudel llega a las mismas conclusiones cuando habla del odio, 
Los moriscos aragoneses, llamados tagarinos en Argel, fueron empleados en el corso y en el mercado de esclavos. Fueron "los más grandes enemigos de los cristianos” ${ }^{39}$, y se cuenta que eran los más crueles. Su rabia contra el cristiano español estaba presente y las heridas siempre abiertas. La venganza les daba la valentía y una voluntad sin igual, más aún al darse cuenta de que habían sido víctimas de una maquinación política y social. Su salida iba a reforzar el esplendor de la España del siglo de los grandes descubrimientos, y su posición en la Europa contrarreformista se iba a consolidar. Eso es lo que pensaba el círculo del Rey.

En las alturas, se decía que la gran decisión iba a sacar a Felipe III de la mala postura en la que se había envuelto con las treguas que había firmado con ingleses y holandeses, patria protestante que no pudo aliar a su causa a pesar de todas las concesiones y tras todas las luchas. España se preparaba para volver de nuevo a hacer brillar su escudo gracias a la expulsión de los moriscos, minoría víctima de falsas promesas y de grandes engaños. Pero la verdadera consecuencia iba a ser muy amarga para la sociedad española de los siglos XVII y XVIII.

Salvar a los moriscos había costado a la marina turca grandes sacrificios en hombres y en material. Haber salvado a miles de musulmanes del infierno en que el fanatismo les había hundido, haber hecho pagar muy caro a España su política antimusulmana y los prejuicios materiales y morales, transformando sus costas en lugares inhóspitos, poniendo así en peligro su actividad económica, tal era la satisfacción de los dirigentes de la marina de Argel: "La marina argelina, con el fin de salvar y vengar a miles de musulmanes, iba a tener un papel espectacular" ${ }^{40}$.

Entre 1580 y 1620 Argel disfruta de un período de esplendor. La capital corsaria, como la designaban los países cristianos de las riberas mediterráneas, se beneficia a la vez de la concentración de la piratería y de una revolución técnica de importancia decisiva ${ }^{41}$. Aquella revolución técnica precisamente en aquel período tenía, sin lugar a duda, que ver con la llegada de los expulsados de España. Éstos habían llegado con toda su

de la ira de los moriscos hacia los cristianos españoles que les habían echado fuera de su tierra natal y la de sus antepasados. La marina y el corso les ofrecieron ocasiones para vengarse.

39 Pedro Ordóñez de Ceballos, Historia y viaje del mundo, Madrid, 1616, p. 37.

40 Moulay Belhamissi, ob. cit., tomo III, p. 149.

41 Braudel, ob. cit., p. 307. 
sabiduría y su buena voluntad, a pesar de su estado de ánimo. Cooperaron con los amos de la capital y se integraron en la sociedad sin muchos problemas, aunque se afirmaba que no se mezclaban con las demás poblaciones de Argel, para salvaguardar una parte de su civilización "que corría el peligro de derretirse bajo la presión de las mezclas con los elementos alógenos" ${ }^{42}$.

Es lo que ocurrió igualmente en la ciudad de Tremecén, capital de los Beni Abdelwad. Para salvar la existencia de su comunidad y mantener las distinciones, aunque con el deseo de integrarse, se mantuvo la endogamia en la mayoría de los casos. En efecto, los moriscos llegados después de la expulsión casaron a sus hijas e hijos con gente de su estatus y origen, facilitando la supervivencia de las costumbres, de los usos y de las tradiciones, levantando de este modo una pared alrededor de sus lugares de residencia, reservando sin embargo momentos de salidas e intercambios con sus vecinos prójimos.

El hecho de no mezclarse con los autóctonos no les quitaba la fama de ser un pueblo trabajador y muy activo. Eran artistas en el terreno de su saber, tenían mucho placer por hacer las cosas a su manera, y las hacían bien:

Argel pudo atraer, por varias razones, a esos nuevos inmigrantes dotados de fondos financieros, de competencias profesionales que faltaban al Pachalik. Su presencia es múltiple. La encontramos, según nuestros documentos, en todos los tipos, raíses corsarios, propietarios de bienes, comerciantes, administradores de aguas, alfaquíes ${ }^{43}$.

En efecto, participaron en la expansión social y económica de la ciudad. Su punto de vista en tanto que expertos se tomaba en cuenta y era muy solicitado; se los encontraban hasta formando parte de las asambleas de mercaderes de la ciudad ${ }^{44}$.

Las inversiones andalusíes eran particularmente visibles en el comercio, en el cual estaban predispuestos: almacenes, locales, bienes mobi-

42 Farid Khiari, Vivre et mourir en Alger, París, Harmattan, 2002, p. 137.

43 Ibid.

44 Ibid. 
liarios y terrenos. Estaban "implicados en todos los niveles de la economía urbana” ${ }^{45}$, afirmaba Farid Khiari.

\section{Tenes}

La provincia de Tenes era la segunda en el reino de Tremecén en dirección hacia oriente. De gran fertilidad y riqueza ganadera, a medio camino entre Orán y Argel, tenía una situación estratégica. Puerto comercial de primera línea, era el horizonte ambicionado desde comienzos del xvi por los españoles y los otomanos.

Tenes estaba situada en un fondo bastante salado, a una pequeña distancia del mar. Estaba bañada por un arroyo importante, y estaba reputada por la gran cantidad de trigo que se exportaba hacia Europa. Sin embargo, su rada estaba demasiado expuesta al viento del oeste y del norte ${ }^{46}$.

El gobierno de Tenes estaba en manos de la dinastía zianí, igual que la ciudad de Tremecén, sede del reino, Tenes tuvo que pagar tributos a la Corona castellana después de la toma de Orán. España quería añadir aquel puerto a sus adquisiciones costeras, ya que serviría de fortificación para proteger Orán y Mazalquivir. Aquel objetivo no se pudo cumplir por la llegada de Kheireddine Barbarroja y la toma de la ciudad ${ }^{47}$. Ciertamente el puerto de Tenes era muy útil, porque le serviría de depósito para su artillería. Además, los cereales que producía eran necesarios para sostener a Argel $^{48}$.

\section{Cherchell}

Los andalusíes echados de su país también se asentaron en Cherchell. La fortaleza se convirtió en su cuartel general. Después de haber caído en ruinas, se vio repoblada por la comunidad andalusí.

Los otomanos tomaban una gran parte de su abastecimiento de la ciudad. Había fábricas de galletas, talleres de cuerdas y velas, depósitos

45 Idem., p. 144.

46 Idem., p. 146.

47 Beatriz Alonso Acero, Sultanes de Berbería en tierras de la cristiandad. Exilio musulmán, conversión y asimilación en la monarquía hispánica (siglos Хи y ХVII), Barcelona, Bellaterra, 2006, pp. 123-124.

48 Luis del Mármol Carvajal, Historia del rebelión y castigo de los moriscos del reino de Granada, BAE, tomo xxi, f. 210. 
de madera de construcción que provenía de los montes de la región. Esto explica el terreno en el que los habitantes se convirtieron en maestros de la construcción de embarcaciones, como señalábamos antes; de ahí su actividad directa en empresas marinas y corsarias.

En 1531, Doria decide atacar Cherchell con la firme esperanza de instalarse allí, después de la pérdida del peñón de Argel ${ }^{49}$. Desgraciadamente para él y para la Corona española, no lo logró.

Según el doctor Thomas Shaw, aquella urbe era conocida por sus fábricas de acero y su alfarería. Sus casas estaban cubiertas por tejas. Las fuentes las alimentaban las aguas del río Hachem, conducidas por un "gran y suntuoso acueducto, prueba de solidez y de belleza" ${ }^{50}$.

Era difícil encontrar una posición más bella y más ventajosa que la de aquella ciudad. Una fuerte muralla de 40 pies de alto la abrigaba contra todo ataque enemigo. Su puerto era de forma circular. En su entrada se elevaba una pequeña isla de rocas donde los barcos encontraban refugio contra los vientos del norte y del nordeste ${ }^{51}$. Había también huellas del pasaje de los romanos en la ciudad, ruinas soberbias que probaban "que Cherchell es verdaderamente la Julia-Caesarae romana" 52 .

Con toda evidencia, la región estaba bien regada y era muy fértil, y Argel, en tanto que capital de la Regencia, contaba mucho con Cherchell y otras ciudades como Blida, Medea, Kolea, Miliana, que trabajaban para ella.

\section{Blida}

El origen andalusí de la ciudad de Blida no parece albergar ninguna duda. Esta ciudad, ubicada a unos 50 kilómetros al sur de la capital, fue testigo de la instalación de los moriscos expulsados, ayudados por los otomanos de la Regencia. Aquellos andalusíes construyeron los elementos principales de una ciudad musulmana, o sea, los baños, los hornos y la mezquita. Dieron un nombre a esta última: "la gran mezquita de los Turcos", una forma de dar las gracias a las autoridades que les habían

49 Belhamissi, op. cit., p. 47.

50 Ob. cit., p. 148.

51 Idem., p. 149.

52 Idem., p. 150. 
facilitado su instalación y, además los protegía a diario ${ }^{53}$.

A principios del siglo xviII, un religioso llamado Francisco de Ximénez, de visita en Blida, la describió así:

Los jardines procuraban un placer para los ojos por la abundancia de árboles frutales y silvestres que la poblaban con tantas delicias [...] me encantan. Las pocas casas de campo de los Moros ricos con un techo de estilo español igualmente [...] Es una tradición que los moriscos expulsados de España fundaron ${ }^{54}$.

Se nota en esta descripción similitudes con la imagen que viajeros, naturalistas y soldados hicieron a lo largo de la historia de Tremecén y su región. En cuanto al francés Venture du Paradis, en la misma época, afirmaba a propósito de Blida:

Belide es una de las ciudades más agradables del reino; está a 6 leguas de Argel, en el gran camino que lleva a Mascará. Todas las casas tienen una fuente. Los jardines dan todas las frutas y legumbres que se consumen en Argel. Se celebra todos los jueves un mercado general, donde de todos los alrededores se trae pollos, huevos, frutas secas, trigo y hortalizas ${ }^{55}$.

Francisco Ximénez confirma que los habitantes son moriscos expulsados de España y traídos por los otomanos. Por eso, la urbanización de la ciudad se hizo siguiendo el estilo arquitectónico musulmán español. Venture du Paradis no lo afirma claramente, pero hace alusión a un elemento que es muy típico de aquella arquitectura: la existencia de la fuente en el interior de las casas, en el patio, más precisamente. No sólo crearon la misma urbanización sino que instalaron toda una tradición en la organización de la vida cotidiana, entre otras, el mercado semanal que permitía entretener relaciones de comercio y crear amistades con los vecinos.

\section{Bugía}

Esta ciudad brilló bajo los hamadíes (IOI5-II52). Capital intelectual, se dispensaba allí el derecho y la medicina, las ciencias y la teología. Última

53 Míkel de Epalza, Los moriscos antes y después de la expulsión, Madrid, Mapfre, 1992, p. 227. 54 Idem., p. 227.

55 Citado en Epalza, p. 250. 
y más oriental de las provincias del reino de Tremecén, era un territorio limítrofe con el reino de Túnez y muy influenciado por él.

Con Tremecén fue, a partir del siglo xiII, la ciudad principal del territorio hacia la cual se canalizaron los flujos de los refugiados. Un goteo continuo de mudéjares hispánicos arribó a sus costas y, de allí, hacia las ciudades del Magreb central. En Bugía, la colonia andalusí se instaló en las llanuras cerca del río Sumam, en la zona del mausoleo de Sidi Aisa Adabuki, en las afueras de la ciudad, en tiempos del sultán hafsí de Túnez ${ }^{56}$.

Sus actividades corsarias contra los intereses cristianos hicieron de ella el punto de mira de la monarquía española desde finales de la Edad Media. Por lo tanto, era necesario y vital anejar aquel territorio, después del éxito de la toma de Orán en I509. Consecuentemente, Pedro Navarro entra con gran triunfo en Bugía el 6 de enero de I5Io, y la presencia hispana durará hasta I555. La caída de la ciudad bajo el mando de Salah Raís puso punto final al sueño que entretenían los cristianos de formar un imperio en el Magreb central. Braudel cuenta que la emoción fue tan grande en España, al recibir el anuncio de la pérdida de la ciudad, que se habló durante meses de reconquistarla ${ }^{57}$.

IV. El GRADO DE INTEGRACIÓN DE LOS MORISCOS EN LA SOCIEDAD MAGREBÍ

Los andalusíes tenían un comportamiento muy sutil y las cualidades que se les atribuyeron son la prueba de su refinamiento en el placer de las cosas y su discreción en sus relaciones sociales. Todo eso estaba en relación con su saber ser y hacer. Sus competencias eran múltiples: las ciencias fueron los primeros terrenos que caracterizaron a los musulmanes de España, como metrópolis del saber y de la cultura en el mundo mediterráneo. Todos los países de los alrededores y particularmente cristianos venían a jurar su fidelidad a los monarcas de las diferentes épocas, con el deseo de impregnarse con su saber. La medicina no tenía secretos para ellos, aunque a veces eran tratados de brujos y hechiceros. Sus remedios

56 Idem., p. 226.

57 “Les Espagnols et l'Afrique du nord”, Revue africaine, 1928, núm. 69, p. 368. 
y sus modos de curar eran diferentes de los de los cristianos, sus vecinos, y eran mucho más eficaces, lo que no era del agrado de estos últimos.

La agricultura era su terreno preferido, y contribuyeron a la creación de paraísos agrícolas por donde pasaban y se instalaban. Sus viajes los llevaban a menudo al Magreb central e intercambiaban conocimientos que cada lado de la cuenca aprovechaba, lo que trajo mucho bienestar en las poblaciones de antaño. Aquellos intercambios se volvieron más acentuados con su llegada definitiva.

Numerosos aspectos de progreso material se instalaron con su llegada en las tierras magrebíes, y eso creó resentimiento en la sociedad cristiana que los había expulsado. Un progreso al que se sumaba la actividad corsaria como azote que no olvidaba el error histórico.

\section{El refinamiento y el trato social}

Los andalusíes de Argel fueron objeto de descripción en el pseudo-Haedo. En cuanto a su físico: "son blancos y bien proporcionados, igual que todos los originarios de España" ${ }^{58}$. En lo que se refiere a sus profesiones, dice:

Ejercen un gran número de profesiones diversas, todos sabiendo alguna labor. Unos hacen arcabuces, otros pólvora; hay entre ellos cerrajeros, carpinteros y albañiles [...] Muchos se ocupan del gusano de seda y sus tiendas venden todo tipo de mercería ${ }^{59}$.

A continuación alude a sus sentimientos hacia los cristianos que les hicieron tanto sufrir: "Son todos en general los más grandes y más crueles enemigos que tienen los cristianos en Berbería" ${ }^{60}$. Luego, se precisa que eran mudéjares de Granada y otras ciudades de Andalucía (Sevilla, Málaga, Córdoba, Toledo), y tagarinos de Aragón, Valencia (Albatera, Novelda, Alicante, Elche), Castilla, Murcia y Cataluña. Habían llegado, según lo que se dice, desde Marsella y otros puertos de Francia, en barcos franceses.

No hay que olvidar que, los andalusíes de Argel llegaron también en los barcos otomanos desde las costas levantinas. El pseudo-Haedo afirma entonces que los andalusíes habían llegado a Argel embarcándose en el

58 Haedo, ob.cit., p. 54.

59 Ibidem.

60 Ibid. 
puerto de Marsella. Sabemos muy bien que, al organizar la expulsión, el gobierno español hizo de tal forma que cada ciudad pudiera embarcar a sus moriscos en el puerto más cercano posible. Andalucía es la región más alejada de la frontera francesa; ir a pie del sur hasta el norte de la península, en las condiciones de la época, y vistas las circunstancias del acontecimiento, no parece una empresa creíble. Es evidente que la información es inexacta, a menos que el autor de la Topografía de Argel se refiera a una situación bastante anterior, o sea, antes de la expulsión final, o sencillamente a los moriscos del norte peninsular.

\section{Las cualidades del comportamiento}

Los moriscos, al llegar al Magreb central, eligieron sus lugares de instalación después de haber sido dirigidos por las autoridades españolas $\mathrm{y}$ otomanas, unos en las ciudades, otros en las zonas rurales y periurbanas, directamente controladas por estas últimas. Los que eran de origen campesino salieron a las afueras de las ciudades y se acomodaron, creando otra parcela de la tierra de sus antepasados que habían dejado, forzados:

Los musulmanes andaluces nos dan un buen ejemplo del cortejo de plantas que acompaña a toda población que se desplaza, y por el cual una sociedad reconstituye el microcosmo vegetal necesario para su alimentación, su medicina, su vida religiosa, su vida social ${ }^{61}$.

En la vida diaria, Jerónimo Münzer los había descrito de la manera siguiente:

Su práctica religiosa parece de tal cualidad que su vista provoca admiración, su honestidad aparece claramente. Estamos lejos del retrato tradicional del sarraceno, lleno de perfidia y de furia, violento y dominador, que presentaban los textos antes de su derrota ${ }^{62}$.

Notaremos en las palabras de este autor la utilización de sustantivos de cualidades positivas a propósito de los musulmanes de Andalucía, región que visitó durante las etapas de su viaje: admiración, honestidad. Opone a esos sustantivos otros términos que pertenecen a autores de textos

61 Françoise Aubaile-Sallenave, Les jardins arabes, París, Musée d'histoire naturelle, p. 147. 62 Ob. cit., p. 25. 
que trataban de las mismas personas, y que son: perfidia, furia, violento $y$ dominador, todos antónimos de los primeros.

Aquella diferencia tiene un papel muy importante para la imagen del musulmán en la época. Los que no los conocían crearon una imagen negativa según lo que habían oído, sobre todo frente al problema religioso. Y los que los conocían o conocerán, podrán juzgar por sí mismos, sin prejuicios, dándose cuenta de una leyenda negra construida contra el Islam español. Así por ejemplo puede interpretarse de la percepción humana que tiene Cervantes del morisco Ricote, con la valoración de otros autores españoles, como Lope de Vega. Al final, fueron recompensados de una manera trágica, inhumana y cruel. Los echaron como si fueran rebaños contaminados. Fueron maltratados por todos o casi todos. Fueron aniquilados y finalmente, olvidados.

\section{El placer de la poesía y de la música}

Los moriscos llegaron también con su música, que existía con sus predecesores, y que cantaba sus penas. Desde esta tradición se van formando las modernas escuelas musicales del Magreb central: Tremecén, Argel y Constantina. Esta música fue apreciada por su elaboración técnica y compleja instrumentación, hasta consolidarse como la música clásica magrebí:

La música de los moros es más harmoniosa y se ejecuta con más arte que la de los beduinos. Tienen también una variedad más grande de instrumentos que ellos [...] varias especies de flautas y de oboes [...], el rbâb [...], el aud [...] guitarras de diferentes tallas; han perfeccionado el târ de los beduinos[...] Aquella diversidad de instrumentos y su modo de tocarlos no deja de tener mucha harmonía en su música, que ejecutan de memoria ${ }^{63}$.

La música andalusí tradicional, la que nos llegó con aquellos desarraigados, era quejumbrosa y triste. Estaba asociada con su situación de pueblo vencido y dominado. Mas, también era alegre y festiva, y podía consolarles de sus tribulaciones, y al mismo tiempo, les hacía olvidar sus penas. Las palabras y las composiciones de versos daban la impresión concreta de los sentimientos, y trataban del gran poema de la vida humana y

63 Shaw, ob. cit., p. 84. 
de todas sus manifestaciones. Aquella poesía, llamada vulgar o popular, es un tema muy amplio; sus poemas tratan del dogma, de la religión, de las leyendas locales, del culto de los santos, del ardor de la fe, de la alegría, el dolor, la ternura, la pasión, la esperanza, la naturaleza:

Aquella poesía no tiene nada de artificial; es la obra de la naturaleza en toda su espontaneidad; nos presenta un cuadro fiel de la sociedad del tiempo, con sus creencias religiosas, sus ritos, sus recuerdos y sus sentimientos más verdaderos, los más cándidos ${ }^{64}$.

En cuanto a la música popular, sus cantos eran acompañados por la guitarra, la cual subrayaba las melodías por sucesiones periódicas de acordes, igual que en el flamenco. Los palmoteos de los espectadores — que se convierten en elementos activos uniéndose con los bailarines- eran de uso en las antiguas zambras moriscas. Y finalmente, el olé de los espectadores durante la actuación de un cantaor flamenco tiene su parecido en la música llamada andalusí, expresión corriente y familiar. Se pensó hasta en la etimología de la palabra flamenco, que según Blas Infante tiene su origen en el árabe, fellab en fuga (o sea fellah fugando), y eso calificaría a los moriscos que no salieron de España, que huyeron en el interior del país, mezclándose con los campesinos, los mendigos y los gitanos. Así se planteaba la teoría decimonónica:

La idea que tenemos hoy día a propósito de aquella raza (la gitana), en España, es que desciende de los moriscos que se quedaron, después de la expulsión de la mayoría de los suyos, bajo Felipe III $^{65}$.

Blas Infante, interesándose por la génesis del flamenco, añade otra hipótesis a propósito de la cohabitación obligada de los moriscos y de los gitanos, y sobre la mezcla de las dos etnias y las dos culturas:

Bandas errabundas, cruelmente perseguidas [...], van de pueblo en pueblo y constituyen comunidades [...]. Son bandas enteras de moriscos que se reunieron con ellos, últimos descendientes de hombres que habían

64 Abdelhamid Hamidou, “Aperçu sur la poésie vulgaire de Tlemcen”, Revue africaine, 1936, núm. 79, pp. 1007-1013.

65 Georges Borrow, Los Zincali. Los gitanos en España, Londres, 1840, p. 30. 
pertenecido a las culturas más resplandecientes, volviéndose campesinos en huida ${ }^{66}$.

En las calles de los barrios musulmanes de las ciudades de al-Andalus, tales como Toledo, Córdoba, Sevilla, Granada, la música se oía a lo largo del día. En Tremecén, ninguna fiesta pasa sin una velada musical. La llamada música andalusí hace cantar y aplaudir al compás a viejos y jóvenes. Aquella música tenía su letra cantada con palabras tomadas de poemas, moaxajas y zéjeles, muchas veces con temática del amor udrí. Aquellos poemas reflejaban al mismo tiempo la pena, la desesperación, la alegría, la esperanza, la desgracia, la dicha y la felicidad. La leyenda también cuanta que el placer que sentían los andalusíes por la música fue la causa de su perdición. Se cuenta el caso de la toma de Granada y de su rey Boabdil (Abú Abdalá) que, al ser avisado por sus guardias de la presencia del enemigo en las puertas de su reino, respondió, con palabras que ahora son de una canción magrebí: "Déjate de los problemas hoy, los resolverás mañana, aprovecha el momento presente y el placer de esa noche de delicias".

Aquella música, compuesta por poemas fugitivos nacidos de un capricho o de una circunstancia pasajera, constituye un mosaico de los habitantes, un espejo de sus almas. Reproduce la vida de todos los días, los ademanes y las actitudes familiares ${ }^{67}$. Así, nació el hauzi, música que viene de la palabra hauz que significa "los alrededores de la ciudad", cuyos autores son ésos que se instalaron en los arrabales de las ciudades magrebíes. La nostalgia de al-Andalus como "paraíso perdido" se exalta con la música y letra de este legado que hoy se conserva en todo el Magreb.

Todos los elementos que necesita el compositor de esos poemas cantados dentro de este género están presentes en la ciudad de Tremecén, vieja capital del Islam: monumentos, ruinas, mudos testigos de un pasado glorioso, paisajes encantadores, campos verdes y llenos de flores, inmensas tierras de olivos, de cerezos, de naranjos, de almendros, de granados, con admirables cascadas, aguas corrientes y abundantes, fuentes brillantes, el

66 Blas Infante Pérez, Orígenes de lo flamenco, Sevilla, Juan de Andalucía, 1980.

67 Hamidou, ob.cit., p. 1037. 
murmullo del agua y el canto de los ruiseñores. Todo eso da imaginación de fecundidad inagotable.

\section{El arte de la gastronomía}

El arte culinario hispanomusulmán encontró un terreno favorable en el suelo magrebí. La cocina morisca se caracteriza por la utilización de ingredientes específicos que existen en nuestros platos, los del Magreb central, los siguientes: miel, canela, azafrán, especias olorosas, jengibre, clavo, ajo, cebolla, cilantro, y legunbres ${ }^{68}$.

Los platos azucarados con carne que se preparan con frutas secas o frescas tales como la uva, el albaricoque, la ciruela, la pera, la manzana, vienen de al-Andalus. Las confituras o mermeladas de frutas también, así como los dulces fritos y bañados en miel, tales los makrut, los griwech, la samsa. En cuanto a la ghribiya con aceite y sin huevos, se llama en Andalucía mantecado.

La utilización de la almendra, fruto seco apreciado en dulces y platos azucarados, es prueba de refinamiento en las costumbres. Es una preparación frecuente en la sociedad argelina, y es el principal ingrediente de las grandes ocasiones, por ejemplo en el mes de ayuno, en los noviazgos, en las bodas, etc.

La tortilla con cebolla, pimienta y tomate se parece también mucho a la tortilla española de hoy. Igualmente, podemos hablar de la receta que utilizamos para cocer el arroz; tiene muchos ingredientes comunes con los arroces mediterráneos: el ajo, el tomate, el pollo y el azafrán, entre otros.

El aceite de oliva era el producto de base de los platos andalusíes de la península; esa tradición se perpetuó a lo largo de los años y de los siglos, también en la gastronomía argelina. Este aceite se utilizaba no sólo para cocinar y cuidar así de la salud, sino que se usaba también para el cuidado de la belleza del pelo y de la cara, y al mismo tiempo servía de remedio para varios daños corporales y dietas. Por todas estas utilidades, los cris-

68 En la región oeste del Magreb central se utiliza mucho el garbanzo en casi todos los platos con salsa y carne, acompañados de verduras. El ajo y la cebolla son ingredientes primordiales y de base para toda comida. En las regiones costeras, el pescado es una tradición, y comerlo a la española también; la costumbre se perpetúa hasta hoy. Los habitantes de estas regiones utilizan no sólo las recetas sino también el vocabulario de origen hispánico. Cf. Josette Badache-Delliot, La cuisine algérienne, París, Bachari, 2007. 
tianos veían en el producto algo de magia y condenaban a los médicos que aconsejaban su utilización en aquellas situaciones excepcionales, y por lo mismo, su consumo cotidiano en las comidas y cenas de los mudéjares $\mathrm{y}$ de los moriscos ${ }^{69}$.

Las regiones de Beni Saf, Orán y Mostaganem guardaron ciertas costumbres culinarias, $\mathrm{y}$ todo un vocabulario de cocina, de pescadores $\mathrm{y}$ de barcos. Como es sabido el español moderno se introdujo con la llegada de población migrante española durante la colonización francesa. No obstante, probablemente quedasen reminiscencias lingüísticas de la lengua romance hablada por los moriscos. vocabulario un poco alterado por el tiempo y las generaciones.

La herencia espiritual hispanomusulmana es asombrosa cuando se mira de más cerca: crónicas, historias, poesías, estudios filosóficos o científicos, ordenanzas municipales, libros de medicina, reglas para el ajedrez, obras de botánica, agricultura o ciencia veterinaria, tratados de astronomía y astrología y libros de recetas de cocina. Por su riqueza y su variedad, con sus especialidades en los diferentes terrenos, se entiende por qué hay tantas similitudes entre las regiones donde se instalaron. Aquellas semejanzas caracterizan cada terreno de competencias en cada ciudad o periferia donde encontraron refugio para sus penas y sus sufrimientos.

\section{Las competencias agrícolas}

Los moriscos atendían el cultivo con curiosidad y vigilancia. Esta afirmación se confirma estudiando el propio territorio ibérico. En efecto, transformaban tierras estériles y de secano en tierras fecundas, llenas de productos y con mucha organización y regadío. El cultivo rey era el trigo, mezcla de diferentes variedades, siete en total. Lo sembraban entre los árboles frutales y utilizaban el regadío. Según la temperatura natural del lugar, se elegía entre el trigo gordo o arisprieto o rubión. El conocimiento de los moriscos a este propósito era intenso y "eran capaces de adaptar variedades de trigo a cualquier tipo de nichos" ${ }^{70}$. Al ser expulsados, aquellos agricultores salieron con todo su conocimiento ecológico y agrícola, el

69 Cf. Simone Chamoux y Sophie Lacoste, Secrets et vertus de l'huile d'olive, París, Ramsay, 2007.

70 T.F. Glick, "Agricultura morisca”, en Norberto Piqueras (coord.), Entre tierra y fe: los musulmanes en el reino cristiano de Valencia (1238-1690), Valencia, Universidad de Valencia, 2009, p. 239. 
cual supieron adaptar a las condiciones locales que encontraron. Es el caso también del maíz, originario del Nuevo Mundo, del arroz que asociaban con el trigo, con la morera en los bordes de los campos, de la caña de azúcar, de la oliva y de la naranja.

En el plan técnico, afirmará Farid Khiari, es necesario constatar que no se hizo nada nuevo de parte de los otomanos más que en las tierras cultivadas por los andalusíes echados fuera de España, y cuya evolución y progreso en el terreno y en otros está más que reconocido ${ }^{71}$. Los ejemplos de la Vega de Granada y de la Huerta de Valencia son ejemplos perennes y conocidos por todos los que se interesaron por la estancia de los árabes en España. Münzer fue testigo de la habilidad y de la eficacia de los sarracenos en el riego y el cultivo de la tierra durante su viaje a España y Portugal, y dio un punto de vista elogioso sobre la admirable capacidad agrícola de los moriscos ${ }^{72}$.

En la región de Argel tenemos el ejemplo de la Mitidja, región agrícola y productiva, hasta en nuestros días. Es "la llanura más bella y más fértil del pachalik" ${ }^{73}$, observará Farid Khiari. Viajando por la región se ve el trabajo serio y ordenado de aquellas tierras. El rendimiento es muy importante, y todos los alrededores se benefician de eso. La vid, los jardines, los naranjales, las plantaciones de limoneros y otros tipos de árboles hacían y hacen todavía las delicias de la región: "Las rosas florecían todo el año, entre las hortalizas más variadas [...] En esta amplia llanura [hay] trigo, cebada, habas, melones, pepinos y todo tipo de legumbres" ${ }^{74}$.

Es conocido que la sociedad musulmana da mucha importancia al agua; este elemento abarca muchas funciones: sirve para beber; es el ingrediente principal en la cocción de los alimentos; sirve para el riego agrícola - jardines y huertas urbanas y periurbanas - y es también importante en las prescripciones de purificación e higiene en nuestras casas, en las mezquitas y en los baños. Por otra parte, la artesanía necesita agua para funcionar: la cerámica, el textil y sus coloraciones, los cueros. Todo eso define la riqueza de una ciudad y le da mucha importancia. Por todas

$71 \mathrm{Ob}$.cit., p. 15.

72 Ob. cit., p. 25.

73 Ob. cit., p. 115.

74 Haedo, ob.cit., pp. 230-231. 
esas razones, hombres ilustres en el terreno de las letras tomaron como tema de sus obras el agua de la ciudad. Es así como el agua y las fuentes están presentes en la vida de los andalusíes. Todas las casas tienen su propia fuente, su propio manantial, y la vida cotidiana gira alrededor del agua, presente y omnipotente. Es una costumbre ancestral que continua existiendo, en relación primero, con el clima y las costumbres higiénicas de los musulmanes, segundo, con el amor a la naturaleza, las flores, los árboles, las plantas decorativas, el suelo de los jardines con su césped, y tercero, con el amor al trabajo fino, paciente y continuo de este pueblo.

El agua, elemento primordial para la vida, fue la mayor preocupación de los expulsados, cuando se instalaron en suelo magrebí. En este sentido, el acueducto de Argel fue construido por cierto morisco cuyo nombre era Usta Musa entre i6ıo y i6ıг, en tiempo del reino del Pacha Mustafa Kusa (I6ro-I6I3). Su edificación tenía dos razones principales: el flujo de los inmigrantes que no cesaba de crecer, y con el fin de no depender únicamente de los estanques de aguas pluviales:

Como esa ciudad no tenía más agua que el de las lluvias, lo que era insuficiente, en i6Ir, un moro andalusí propuso hacer venir a ella las aguas de un manantial que estaba a un cuarto de hora de la ciudad, cerca del castillo del Emperador. El proyecto se ejecutó y desde aquel momento se ve cantidades de fuentes en la ciudad ${ }^{75}$.

En la región de Tremecén encontramos las tierras de Uled Sidi Ali Belhadj, que son tierras montañosas pero muy productivas. Allí hay terrenos llenos de cerezos y, en primavera, el paisaje es una delicia: los árboles están llenos de flores blancas, nos creeríamos en invierno con su abrigo de nieve. Y en verano, los árboles cambian de color y se vuelven rojos, llenos de cerezas que atraen la vista e invitan a la degustación.

Ain Fezza es una tierra que produce muchas variedades de legumbres, verduras y su sabor es único, porque el agua utilizada proviene de las fuentes y de los manantiales de los alrededores. Ain Fezza está situada más allá del Urit, conocida por la abundancia de sus aguas.

Varios productos fueron introducidos por los musulmanes de España en estas regiones, tales como el arroz, la caña de azúcar, las variedades de

75 Epalza, ob. cit., p. 238. 
trigo que se cultivaron según el tipo de terreno: limo, rubión, chamorro, gordo. Variedades de habas también fueron introducidas, igual que las judías o fasoles. De los estados de ultramar, es decir del Nuevo Mundo, tomaron la patata, el tomate, las frutas exóticas, la vainilla y otros condimentos propios del terreno de la cocina.

Se producía también el aceite de oliva gracias al trabajo diario de los campesinos. El higo también fue un producto muy apreciado, y lo sigue siendo hoy. Prueba de ello es que esta fruta se consume hasta el día de hoy de forma abundante en confituras y mermeladas; es una tradición que pervive en la sociedad argelina ${ }^{76}$.

Los refugiados atendían especialmente la canalización y el reparto de las aguas con mucho cuidado. Instalaron todo un sistema y un régimen de riego por donde quiera que se instalaran: "son muy ingeniosos para construir conductos de agua" ${ }^{77}$. Observaban los cambios que originaban las lluvias o las sequías, y dejaban las tierras reposar en septiembre para barbecharla: "son muy eficaces para el cultivo de la tierra y de los campos [...] y son gente de palabra, justos y fieles" 78 .

Aquellas cualidades que les reconocían los viajeros extranjeros en España revelan el verdadero lado de los musulmanes del periodo cultural postandalusí. Por oposición a este punto de vista, los vecinos y personalidades políticas y religiosas de la península no veían sino el lado negro, y acusaban a los nuevos conversos de mentirosos, de pérfidas y de intrigantes para la perdición del "muy cristiano Estado hispánico", creando de forma paralela una leyenda negra contra el mudéjar-morisco.

\section{La medicina}

Los andalusíes alcanzaron la excelencia en diferentes disciplinas científicas. Herederos directos de un saber centenario, los moriscos transmitieron, en la medida de sus posibilidades - las posibilidades de una comunidad prácticamente clandestina- este valioso legado. En cuanto a la medicina, la taifa de Denia fue un importante centro científico en el

76 Existe también el higo chumbo que es un producto natural en todos los países de las riberas mediterráneas.

77 Münzer, ob. cit., p. 80 .

78 Münzer, ídem., p.84 
siglo XI, encontrándose miembros de notables familias como los Avenzoar, quienes practicaron la medicina durante tres generaciones. Después de la conquista, los musulmanes más reputados, la élite en el terreno científico e intelectual, marcharon hacia el norte de África e hicieron que la medicina y sus estudios fueran cada vez menos cultivados en la península, desarrollándose sin embargo en el Magreb. Eso contribuyó a una decadencia de la profesión, apoyada por la instalación de los musulmanes en aljamas en zonas rurales y montañosas del interior del país. Luego, la discriminación social y religiosa y la marginalización acabaron el trabajo, y los pocos que siguieron practicando la medicina fueron considerados como curanderos ${ }^{79}$.

Dicho lo cual, no se puede negar que la medicina fue también un terreno de actividad morisca, y numerosos médicos ejercieron en la capital de la Regencia: "No es un azar si encontramos médicos andalusies" ${ }^{80}$.

Durante su estancia en España, a los médicos y cirujanos musulmanes los llamaban para consultar no sólo los enfermos de su comunidad, sino también los de sus vecinos, los cristianos viejos. Hasta Felipe II hizo llamar a un médico morisco para curar a su hijo Felipe III (precisamente quien ordenará más tarde la expulsión ${ }^{81}$ ). Se reconocían sus competencias, aunque más tarde, en la época de las persecuciones, se les acusaron de todos los daños, entre otros, el de practicar y administrar remedios mediante magia y brujería.

\section{La arquitectura}

En cuanto a la arquitectura, todavía está presente y cautiva el estilo arquitectónico norteafricano en su vinculación con el legado andalusí. En el Magreb central, a través de las fuentes epigráficas, como afirma Samia Chergui ${ }^{82}$, la primera generación de arquitectos moriscos se ilustró, a lo largo del siglo Xvir, por su contribución activa en los más importan-

79 Carmel Ferragud Domingo, La práctica de la medicina y la albeitería por los mudéjares y los moriscos del reino de Valencia, en Entre tierra y fe, 2009, p. 325.

80 Khiari, ob. cit., p. 141.

81 Ferragud Domingo, ob. cit., p. 334.

82 Tres epigrafías murales atribuyen al maestro Musa, de su propio apellido Musa al-Yasri al-Andalusí al-Himyari, diferentes edificaciones entre 1627 y 1633. Véase Gabriel Colin, Corpus des inscriptions arabes et turques de l'Algérie, París, Ernest Leroux, 1910, p. 112. 
tes proyectos de urbanización de la ciudad, a través de la construcción de varios edificios de interés mayor. Durante el siglo Xviı, y según las fuentes de archivos otomanos, resalta que una segunda generación de maestros de obra se implicó en el mantenimiento y la conservación de bienes muebles ${ }^{83}$.

\section{a) El hábitat}

En lo que sigue, describiremos el modelo tipo de vivienda morisca. En la entrada de las grandes casas, encontramos primero un porche con bancos por cada lado. Más adentro, hay un patio abierto cuyo suelo está hecho con mármol o con otra materia de la misma naturaleza ${ }^{84}$. Las escaleras se encuentran a veces en el porche, otras veces en la entrada del patio.

Cuando la casa tiene un piso o más, la escalera continúa en una esquina de la galería hasta el último piso de la casa. Al fondo de la escalera hay una puerta que se mantiene cerrada, por higiene y seguridad.

A veces, del lado de la calle, hay un solo balcón, o una ventana con celosía, que no se abre sino en caso de la celebración de ciertas fiestas: bodas, circuncisiones, cumpleaños del nacimiento del Profeta, fiesta del nuevo año lunar, el fin del mes de Ramadán, el sacrificio del cordero y el regreso del peregrinaje de los lugares santos del Islam $^{85}$.

La parte superior de las casas es siempre llana y cubierta con buena yesería de terraza de donde proviene su nombre en lengua francesa. Aquella terraza está rodeada por dos muros, uno al exterior y otro en el interior, o de apoyo. Las terrazas sirven para todos los usos domésticos, tal como extender la ropa, secar los higos y las uvas para el invierno. Se toma el aire también por la noche; se discute con la familia o con los amigos, y se reza también.

b) Las calles

El pseudo-Haedo describe las calles de Argel así: "Todas las calles, más estrechas que las más estrechadas de Granada, de Toledo o de Lisboa, pueden

83 Samia Chergui, "Les morisques et l'effort de construction d'Alger aux XVII è et XVIII Cabiers de la Méditerranée, 2009, núm. 79, p. 317.

84 Shaw, ob. cit., p. 86.

85 Idem., p. 88. 
librar pasaje a un solo caballero, pero no a dos hombres de frente" ${ }^{86}$.

Se destaca en estas líneas el carácter de las calles angostas de la capital, carácter similar que se ve en algunas calles de ciudades de España y Portugal, sitios que fueron urbanizados por musulmanes.

Julio Caro Baroja, por su lado, hace la descripción de los poblados, y encuentra puntos comunes entre Granada y las ciudades del Magreb central, principalmente en la disposición de las calles, los patios, los estanques, los balcones. Describe la ciudad primero, luego entra en los detalles de las cosas diarias:

Los pueblos se hallan en cuestas, son incómodos. Están constituidos por calles y casas pequeñas y mal acondicionadas, aunque no dejaban de reconocer su encanto. Hay muchas calles con salidas o sin salidas; las calles son angostas [...] Jardines, fuentes en patios, estanques. El balcón tenía mucha importancia (aparece en los romances moriscos y en la literatura musical $)^{87}$.

De todas las artes, de la que probablemente entienden mejor los mudéjares es de la arquitectura, afirma el doctor Shaw. Y para los moros, la cosa a la que más importancia se ha de dar es a la vivienda, el estar cómodos y ampliamente instalados:

Son siempre grandes puertas, apartamentos con mucho espacio, pavimentos de mármol, patios rodeados por grandes murallas, y a veces orneados con una fuente en el centro, distribución muy conveniente con la naturaleza del clima ardiente de aquellas regiones, y con el humor celoso de los hombres que las habitan ${ }^{88}$.

La civilización hispanomusulmana derramó su brillo sobre Tremecén y otras ciudades del norte de África, notaremos el ejemplo de Fez, capital del Magreb extremo de la época, bajo el mando de los meriníes, primos de los zianíes del Magreb central. Su arte aparece en las mezquitas, en las madrasas y en las tumbas de los cementerios ${ }^{89}$. En Argel, el morisco Sulayman al-Shwihad, rico comerciante y experto inmobiliario, fue

86 Haedo, ob.cit., pp. 46-48.

87 Julio Caro Baroja, Los moriscos del reino de Granada, Madrid, Alianza, 2003, pp. 216-218.

88 Shaw, ob.cit., pp. 85-86.

89 André Miquel, L'Islam et sa civilisation, París, Armand Colin, 1977-1990-1996, tomo III, p. 83. 
nombrado amin el-umana (síndico de los sindicatos de todas las profesiones) entre i609 y i626. Esta función será ejercida hasta el siglo XVIII por miembros de su misma familia, sus hijos, Yusuf y luego Mohamed, y por fin Mustafa ben Ahmed ben Mohamed, le sucedieron (el último fue en el año de I750). Este hecho habla por sí mismo a propósito de las competencias de aquellos personajes en el terreno de los bienes muebles $^{90}$. Esos maestros habían tomado a cargo un importante patrimonio arquitectónico variado; muchas casas, tiendas y fondas ${ }^{91}$.

\section{c) El jardín}

El jardín, en la vida del morisco, es también muy importante. Es el primer elemento de la composición arquitectónica: "Es el lugar donde el jardinero puede observar y actuar minuciosamente y con más precisión posible. Se encuentra en general al exterior del perimetro de las viviendas, al borde de los arroyos y de los ríos" 92 . En efecto, los sarracenos encuentran mucho encanto en los jardines, y darán prueba de tanta generosidad para plantarlos y regarlos que no se podrá hacer mejor ${ }^{93}$.

Un bello jardín con fuentes, piezas de agua y pequeños arroyos con agua corriente, tan soberbiamente arreglado por los moros, no hay otra cosa más hermosa en el mundo, dirá el mismo geógrafo, encantado por la vista de los jardines tan bien entretenidos de estos ${ }^{94}$.

Así, poco a poco, estos musulmanes españoles reconstituyeron el ambiente que les quitaron con crueldad y, se fueron fundiendo en el tronco de su raza dejando de existir como grupo aparte para la historia.

\section{La artesanía morisca}

Dentro de la alfarería, los moriscos tenían fama de ser diestros en los oficios manuales, por ejemplo en el terreno del trabajo del cuero, en el sector del calzado como los zapateros y los cordeleros. Se destacaban

90 Chergui, ob. cit., p. 314.

91 Idem., p. 311.

92 Vincent Lagardère, Campagnes et paysans d'Al Andalus, VIII'-XV’ s., París, Maisonneuve et Larose, 1993, p. 65.

93 Münzer, ob. cit., p. 94.

94 Idem., p. 90. 
también en el sector del textil como tintoreros, sastres. Tenían por otro lado manufacturas de armas. Eran además yeseros, ebanistas ${ }^{95}$, trabajaban la cerámica de reflejos dorados; eran también colchoneros, cuchilleros, curtidores, caldereros y herreros.

a) El gusano de seda

El gusano de seda y el trabajo de la seda eran su especialidad y su comercio era fundamental. Se sabe que con su llegada, la seda de Tremecén mantuvo una competencia permanente con la de Granada y la de Toledo. La seda española no pudo competir con la de Tremecén, y eso decayó sobre la producción y la rentabilidad del producto. Había ciudades cuya actividad artesanal reposaba sobre el cultivo y el trabajo de la seda; después de la salida de los moriscos y con el despoblamiento de aquellas localidades de fuerte concentración musulmana, la fabricación del producto disminuyó mucho hasta tal punto que la actividad desapareció por completo en varias localidades.

La seda también estaba presente en la capital de la Regencia porque muchos de sus emigrados andalusíes eran artesanos, según el testimonio de $\mathrm{Hess}^{96}$.

b) El tejido

Los moriscos trabajaban el hambel, que es un tipo de manta hecha con lana y fabricada con aparatos artesanales. Es muy típico de la ciudad de Tremecén. Ese producto sobrevivió al tiempo, sigue existiendo y es muy representativo de la artesanía del centro magrebí.

La djelaba también era muy apreciada y muy conocida en los mercados argelinos. La tela de la djelaba dependía del estatuto de la persona en la sociedad. Esta prenda cambiaba según la estación del año, ligera en verano y calurosa en invierno. En todo el norte de África llevar la djelaba es una costumbre, y todas las ciudades que conservan aquella tradición

95 A principios del siglo XVII, Argel contaba con unos 46 artesanos moriscos especialistas en el trabajo de la madera, según Samia Chergui, ob. cit., p. 313.

96 Cf. Andrew Hess, The Forgotten Frontier. A History of the Sixteenth Century Ibero-African Frontier, Chicago, Universidad de Chicago, 1978. 
la fabrican y la producen; es el caso de Nedroma, Tremecén, Bugía, Fes, Meknés y Túnez, entre otras.

c) El bordado

El bordado con hilo de oro y de plata también era especialidad suya, por eso trabajaron en los talleres personales de los monarcas y de los jefes de la época. Confeccionaban sus trajes y sus vestidos de ceremonias y los de sus esposas. Además, el traje de la novia de Tremecén proviene de la tradición andalusí, según los testimonios orales de los ancianos.

La chechia de aquel traje ha sido tema de debate en cuanto a su origen: hay testimonios que dicen que proviene de la tradición turca y otros que dicen que es de tradición andalusí. Nosotros pensamos que como hubo muchas familias moriscas instaladas en Turquía, se entiende el parecido del adorno y la influencia de una y otra tradición, en este caso la morisca y la otomana.

Los moriscos tenían pequeñas empresas de textil y su producción era diversa: chechías, alfombras, gorros, hasta tal punto que esas labores artesanales mezcladas con tradiciones locales y con las múltiples evoluciones técnicas viajaron según las demandas de los mercados de la cuenca mediterránea, de oriente y de la Europa del norte.

Para terminar nuestro artículo, notaremos según todos los testimonios colectados y tratados que, la salida de los moriscos de la tierra ibérica fue beneficiosa para nuestro espacio geográfico, en cuanto a aportes humanos, a influencias socioeconómicas, culturales y políticas. Las huellas que quedan viven todavía, pero bajo un silencio voluntario o no, todo depende de cómo se vean las cosas. Los moriscos, después de haber sido acusados de conservar sus creencias a pesar de su bautizo, tuvieron miedo de serlo por ser cristianos en una tierra musulmana. Por eso, se hicieron discretos al instalarse, en la mayoría de los casos, alejados de la sociedad acogedora. El tema morisco, tabú durante siglos, aparece de nuevo y muestra el renacimiento en el Magreb de una comunidad condenada a la extinción. 
